\title{
La adaptabilidad de la arquitectura industrial en el tiempo. El caso de la desaparecida fábrica de San Ignacio (Los Corra- les de Buelna, Cantabria)
}

\section{The adaptability of the industrial architecture over time. The case of the missing San Ignacio Factory (Los Corrales de Buelna, Cantabria)}

\author{
Sara del Horo MAZA \\ Universidad de Oviedo \\ Facultad de Filosofía y Letras, Campus del Milán \\ Calle Amparo Pedregal s/n. 33011 Oviedo \\ saradelhoyomaza@gmail.com \\ ORCID: https://orcid.org/0000-0003-1942-9790 \\ Fecha de envío: 25/08/2018. Aceptado: 19/10/2018. \\ Referencia: Santander. Estudios de Patrimonio, 1 (2018), pp. 257-272. \\ ISSN 2605-4450 (ed. impresa) / ISSN 2605-5317 (digital)
}

Resumen: El río Besaya (Cantabria) ha sido el motor de desarrollo de varios núcleos de población asentados a lo largo de su recorrido. Uno de los ejemplos más relevantes es el de Los Corrales de Buelna donde, en el último cuarto del siglo XIX, la industria harinera dejó paso a la del metal. Este cambio de rumbo tuvo su reflejo en la arquitectura e ingenios hidráulicos, que quedaron a merced del progreso del sector del alambre y sus manufacturas. La reutilización y adaptación de las instalaciones utilizadas primeramente para la molturación del trigo fueron, entonces, una realidad tan usual como productiva.

Palabras clave: alambre; Forjas de Buelna; harina; José María Quijano; patrimonio industrial; reutilización; Santander; vivienda obrera.

\begin{abstract}
The Besaya river (Cantabria) has been the engine of development of several population centers settled along its route. One of the most relevant examples is that of Los Corrales de Buelna where, in the last quarter of the 19th century, the flour industry gave way to that of metal. This change of direction was reflected in the architecture and hydraulic devices, which were at the mercy of the progress of the wire sector and its manufactures. The reuse and adaptation of the facilities used primarily for the milling of wheat were, then, a reality as usual as productive.
\end{abstract}

Keywords: wire; Forjas de Buelna; flour; José María Quijano; industrial heritage; reuse; Santander; worker housing.

La respuesta ante nuevas necesidades y circunstancias constituye una de las particularidades más reveladoras de las construcciones indus- 
triales. Desde hace varias décadas, esta cualidad inherente del patrimonio inmueble de la industria ha sido puesta de relieve por numerosos investigadores y especialistas de diferentes disciplinas ${ }^{1}$, si bien es cierto que atendiendo, fundamentalmente, al interés y provecho que este aspecto puede revertir en el presente. En esta ocasión, se desarrolla el estudio de un ejemplo concreto, los avatares de una fábrica de harinas ya desaparecida en Los Corrales de Buelna (Cantabria), con el fin de poner el acento en la arquitectura per se y también en el papel que ella misma desempeña en la comprensión del azaroso discurrir de la historia industrial.

\section{Un Río DE HARINA, Y DE ALAMBRE}

A lo largo de sus cerca de cuarenta y siete kilómetros de recorrido, desde su nacimiento en Aradillos, a los pies de Reinosa, hasta su desembocadura en Suances, el río Besaya, además de regar campos, abrevar vacas y alimentar a los ribereños, ha aportado su fuerza para contribuir al despegue económico de la provincia que recorre ${ }^{2}$. Este torrente ha sido considerado el caudal harinero por antonomasia de la otrora provincia de Santander ${ }^{3}$ porque, desde el último cuarto del

1 Entre otros, véanse CANO SANCHIZ, Juan Manuel, "La fábrica de la memoria. La reutilización del patrimonio arqueológico industrial como medida de conservación", Antiquitas, 18-19 (2007), pp. 265-272, [consulta: 23 de agosto de 2018], disponible: https:/helvia.uco.es/bitstream/handle/10396/2956/cano-fabricamemoria. pdf?sequence=1\&isAllowed=y; CAPEL SÁEZ, Horacio, "La rehabilitación y el uso del patrimonio histórico industrial", Documents d'anàlisi geográfica, 29 (1997), pp. 1950, [consulta: 23 de agosto de 2018], disponible: https://ddd.uab.cat/record/16356 y TIELVE GARCÍA, Natalia, "La memoria del pasado industrial. Conservación, reutilización y creación de nuevos equipamientos", E-RPH. Revista electrónica de patrimonio histórico, 19 (2016), pp. 72-99, [consulta: 23 de agosto de 2018], disponible: http:// revistaseug.ugr.es/index.php/erph/article/view/5500.

2 SÁIZ GONZÁLEZ, J. Patricio, "Susurros del Besaya. Artefactos y fábricas de un río cántabro", Actas del VIII Congreso Internacional para la conservación del patrimonio industrial, Madrid, Ministerio de Obras Públicas, Transportes y Medio Ambiente, 1995, pp. 411-421.

3 “Uno de los ríos más importantes de la provincia por su extensión dentro de ella misma y por los puntos que recorre [...]. Este río, notable también por los saltos de agua que se han aprovechado para las fábricas de harina", en RÍO SAINZ, José Antonio del, La provincia de Santander, Santander, Imprenta de Salvador Atienza, 1875, p. 129. 


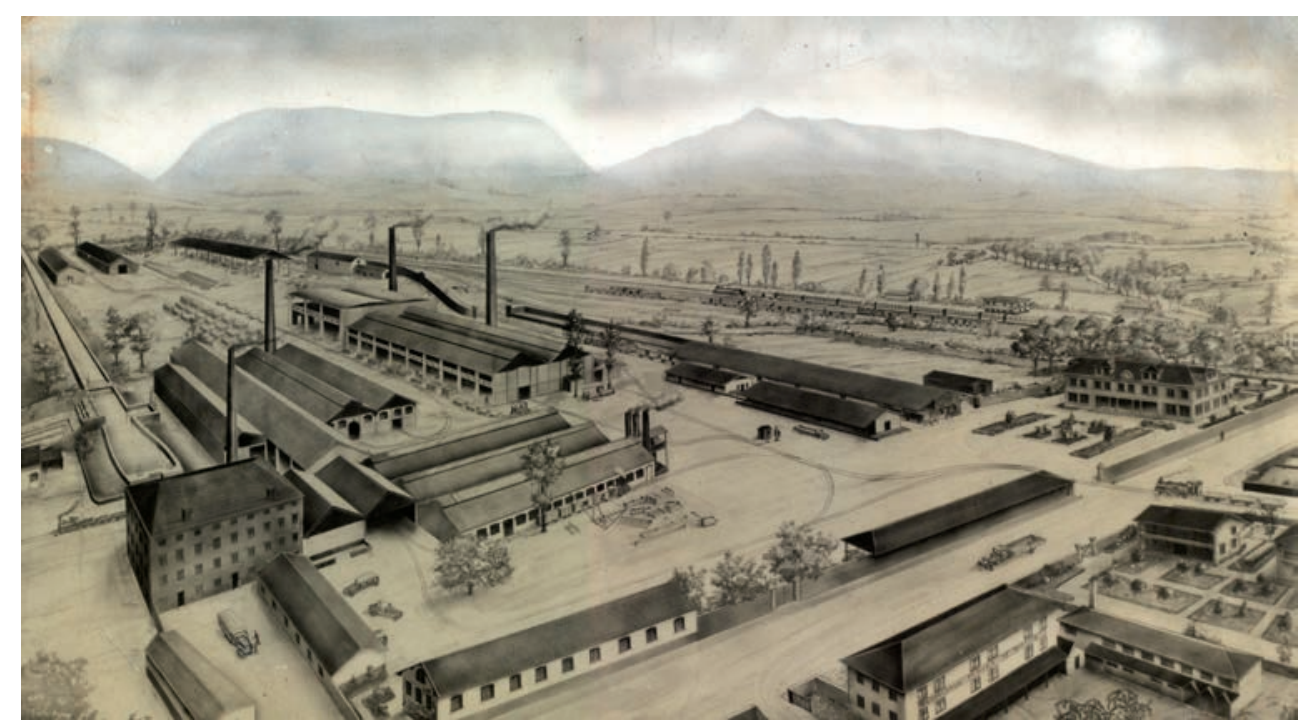

Fig. 1. Vista general del complejo de Arriba, con la fábrica de San Ignacio en la esquina inferior izquierda. Autor desconocido. 1928. Archivo de Trefilerías Quijano S.A.

(Grupo CELSA). Los Corrales de Buelna

siglo XVIII, su abundante caudal y los buenos saltos de agua propiciaron la instalación de diferentes ingenios y artilugios destinados a la molturación del trigo procedente de Castilla. Sin embargo, un siglo después, la competencia de productos más baratos procedentes de ultramar, amparados por la liberalización del comercio internacional y por la revolución de los transportes, provocó la contracción del mercado y la ramificación hacia otros sectores.

Uno de ellos fue el del metal, ubicándose en el Valle de Buelna el mejor ejemplo de cuantas iniciativas se desplegaron en toda la provincia ${ }^{4}$. Un abogado de formación, José María Quijano Fernández (1843-1911), fue quien inició la actividad, precisamente en una casa de molinos situada en el barrio de La Aldea que había heredado de su padre, José Felipe Quijano y Moncalián (1804-1859). Las cuatro ruedas instaladas en el edificio sirvieron, gracias a un complejo mecanismo de transmisiones, para iniciar la producción de puntas de París, en el otoño de 1874. En los años siguientes, el establecimiento de las Forjas de Buelna experimentó un rápido crecimiento, tanto en el número de

4 HOYO MAZA, Sara del, El industrial José María Quijano y su legado (1873-1950): de la fabricación de puntas de París a Nueva Montaña Quijano S.A., Oviedo, Universidad de Oviedo, 2012. 
operarios y de máquinas como en los índices de producción y ventas, fruto de la buena acogida de los artículos en el mercado nacional. Claro y preciso, en otoño de 1879 el corraliego trasladó al papel un límpido balance de estos primeros años de faena, aderezado con los proyectos futuros que habrían de ocupar sus horas en las próximas décadas. Entonces, escribía que "hoy lo que deseo es quitar trabajo a mi atención para dedicarla a otros ensayos de industrias análogas, a fin de poder formar con el tiempo una fábrica completa de lo que llaman los franceses clouterie et trefilerie; es decir, clavazón en todas sus especies, alambres y otros accesorios" ${ }^{5}$.

\section{REINVENTAR LA ARQUITECTURA INDUSTRIAL}

La producción harinera del Valle de Buelna tiene uno de sus máximos exponentes en la fábrica de San Ignacio, aunque, curiosamente, no por el interés de su molienda dada su tardía y anormal corta vida, sino por su trascendencia en el desarrollo de otro sector, el de la industria metalúrgica. Esta instalación comenzó su andadura ligada a la sociedad Rosillo, Camus y Compañía, fundada en 1858 por Fernando Rosillo Gómez y Francisco Camus Pérez con un capital de 1.68 millones de reales $^{6}$, gracias a la unión de caudales reunidos en los comercios de Santander y Cuba. Dedicada a la importación y a la exportación de productos primarios, en especial de azúcar, cacao y harina, en febrero de 1860 estaba dirigida por Joaquín Lecanda Chaves ${ }^{7}$, quien se mantuvo al frente durante no mucho tiempo, dado que fue declarado en estado de quiebra por el Real Tribunal de Comercio de Santander y su partido, el 1 de febrero de $1865^{8}$.

Tras su constitución, la empresa acometió la conversión en factoría de alguno de los no más de diez molinos que jalonaban el curso del río Besaya a su paso por Los Corrales de Buelna9 ${ }^{9}$ En concreto,

5 BUSTAMANTE QUIJANO, Ramón, José María Quijano: vida y obra de un hidalgo emprendedor, Santander, Nueva Montaña Quijano, 1986, pp. 150-151.

6 HOYO APARICIO, Andrés, Todo mudó de repente. El horizonte económico de la burguesía mercantil en Santander (1820-1874), Santander, Universidad de Cantabria y Asamblea Regional de Cantabria, 1993, p. 131.

7 Boletín Oficial de la Provincia de Santander, núm. 24, 24 de febrero de 1860, p. 1.

8 Boletín Oficial de la Provincia de Santander, núm. 96, 8 de febrero de 1865, p. 2.

9 ANSOLA FERNÁNDEZ, Alberto y SIERRA ÁLVAREZ, José, Caminos y fábricas de 
se trataba del inmueble con tres ruedas de moler que estaba situado en el paraje conocido con el nombre de La Horcada, al sur del municipio, y que era propiedad del concejo en el momento en que se confeccionó el Catastro del Marqués de la Ensenada (1750-1754) ${ }^{10}$. En el año 1862, en el término municipal existían, además, ocho molinos harineros que ocupaban a otros tantos operarios y tenían un valor de ochenta mil reales; a su vez, la fábrica de harinas molía con seis piedras, empleaba a catorce trabajadores y se tasaba en la cantidad de trescientos noventa mil reales ${ }^{11}$. Según Antonio María Coll y Puig, seguía en activo en $1875^{12}$ y, al menos desde 1879 y hasta 1881 , cuando muy probablemente cesó su actividad, estaba al frente de la misma Vial Plasencia Fernández ${ }^{13}$.

\section{1. Un nuevo horizonte}

La primera referencia documental localizada que conecta el nombre de José María Quijano con la fábrica de harinas de San Ignacio data del 16 de diciembre de 1877. Se trata de una compraventa legalizada en Los Corrales de Buelna por el notario Anselmo Mata y Quijano, y en la que el industrial participó en concepto de apoderado de los propietarios de la misma, los hermanos Camus Pérez y Rosillo Quintana, según el poder autorizado por el notario público de la ciudad de Santander Urbano Argüeso: Juana, Ignacia y Manuela Camus Pérez, vecinas de Santander; Juan Camus Pérez, de Peñacastillo; Josefa Camus Pérez, de Herrera de Camargo; Lorenzo Camus Pérez, de Cuba, representado por Bartolomé Bengoa y Landa; Federico, Adela y Vicenta Rosillo Quintana, residentes también en la capital de la provincia. Compare-

harina en el Corredor del Besaya: historia, geografía y patrimonio, Torrelavega, Centro de Investigación del Medio Ambiente (CIMA), 2007, pp. 197-198.

10 Archivo Histórico Provincial de Cantabria (en adelante, AHPC), Catastro del Marqués de la Ensenada, legajo 257, p. 13.

11 GIMÉNEZ Y GUITED, Francisco, Guía fabril e industrial de España, Madrid y Barcelona, Librería Española y Librería del Plus Ultra, 1862, p. 142.

12 COLL Y PUIG, Antonio María, Guía consultor e indicador de Santander y su provincia, Santander, Imprenta de Evaristo López Herrero, 1875, p. 252.

13 Anuario-almanaque del comercio, de la industria, de la magistratura y de la administración, Madrid, Carlos Bailly-Baillière, 1879, p. 1.025 y Anuario del comercio, de la industria, de la magistratura y de la administración, Madrid, Carlos Bailly-Baillière, 1881, p. 1.238 . 
cían al acto, también como otorgantes, Teresa de Cos Quijano, vecina de Somahoz y viuda de José Gutiérrez Monasterio, y los tres hijos habidos en el matrimonio: Teodomiro, Servando y Carmen Gutiérrez de Cos. Estos últimos eran dueños de un prado de cerca de cien áreas con arbolado, en el sitio de La Pelambre, lugar de Somahoz, que se encontraba dividido en dos porciones por el cauce que conducía las aguas del río Besaya desde la presa construida al pie del puente de hierro del ferrocarril hasta el campo de La Horcada. El prado, además de tener un censo, estaba cruzado por una servidumbre de carril por donde los vecinos arrastraban maderas de sus montes, contando con dos portilleras de madera en la entrada y la salida para facilitar el tránsito.

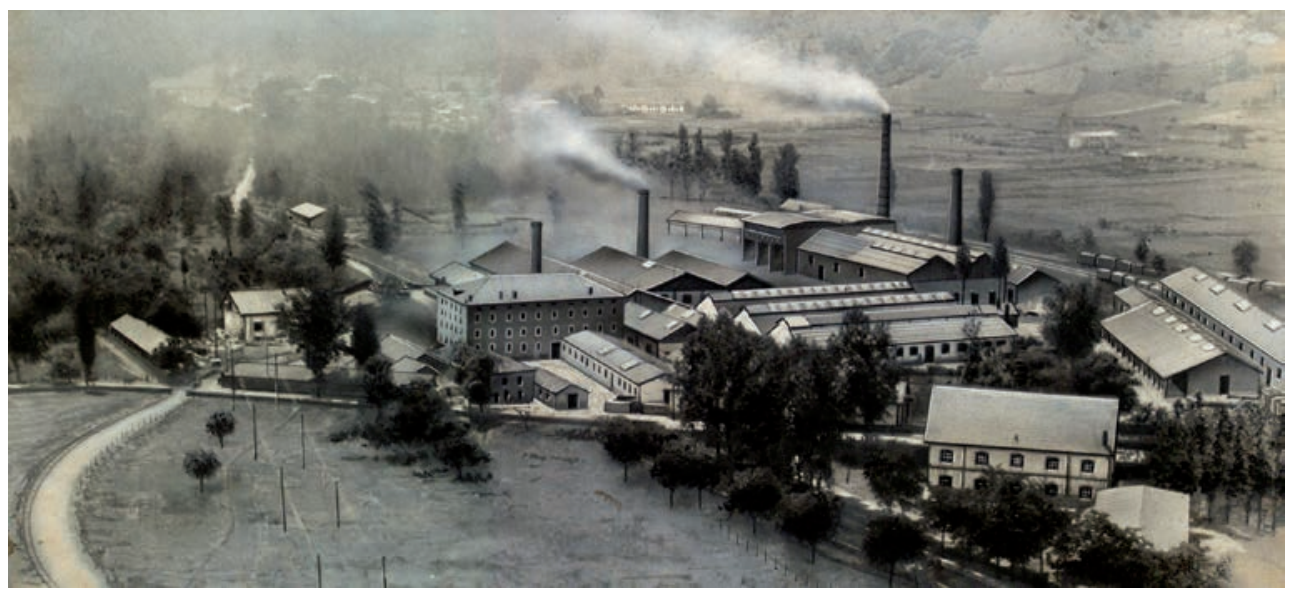

Fig. 2. Fábrica de San Ignacio en el centro de la composición. Autor desconocido. Década de 1930. Archivo de Trefilerías Quijano S.A. (Grupo CELSA). Los Corrales de Buelna

Al parecer, las disputas entre los amos del prado, representados por el procurador Eugenio Ruiz Collantes, y los del inmueble, acerca de las aguas y su conducción por el canal, habían ocasionado un pleito seguido en el Juzgado de Primera Instancia de Torrelavega, en ese momento en grado de ejecución de sentencia. No hizo falta que el ingeniero Eduardo Miera, perito nombrado al efecto, iniciara la dirección de las obras en la presa y el cauce, porque ambas partes llegaron a un acuerdo. La familia Cos aceptaba vender la finca objeto de la cuestión con su arbolado, renunciando a cualquier derecho, por un importe de dieciséis mil cien pesetas, cantidad recibida en metálico con anterio- 
ridad a la formalización de la escritura ante notario. Así, los Camus Pérez y los Rosillo Quintana rubricaron una compra "que hacen como terrenos accesorios a la fábrica de San Ignacio para mejor servicio de esta"14.

\begin{tabular}{l|c}
\multicolumn{1}{c|}{ Propietario } & Participación \\
\hline Vicenta Rosillo Quintana & $26,91 \%$ \\
\hline Adela Rosillo Quintana & $9,87 \%$ \\
\hline Federico Rosillo Quintana & $9,87 \%$ \\
\hline Juan Camus Pérez & $9,75 \%$ \\
\hline Lorenzo Camus Pérez & $9,75 \%$ \\
\hline Josefa Camus Pérez & $9,75 \%$ \\
\hline Manuela Camus Pérez & $9,75 \%$ \\
\hline Ignacia Camus Pérez & $7,78 \%$ \\
\hline Juana Camus Pérez & $6,67 \%$
\end{tabular}

Tabla. Propietarios de la fábrica de harinas de San Ignacio y porcentaje de participación de cada uno de ellos, a 16 de diciembre de 1877. Fuente: elaboración propia a partir de Archivo Histórico Provincial de Cantabria, protocolos notariales, legajo 7293, pp. 416-423

Todavía habrían de pasar casi seis años para que José María Quijano se hiciera con una de sus más preciadas posesiones. Ya en agosto de 1883, era público que había comprado la fábrica de harinas de San Ignacio, porque la noticia circulaba de boca en boca por el pueblo. Para adelantar futuras gestiones, y ganar tiempo antes de la oficialización de la adquisición, el día 20 del mismo mes dirigió una instancia al Ayuntamiento de Los Corrales de Buelna en el que hacía evidentes sus aspiraciones ${ }^{15}$. Y es que las nuevas instalaciones requerirían

14 AHPC, protocolos notariales, legajo 7293, pp. 416-423.

15 "El objeto del exponente, al hacer esta adquisición, es el establecimiento de hornos de fundición con los aparatos necesarios para laminar el hierro fundido y producir el alambre de todas clases, con lo cual, al mismo tiempo que adquiere base sólida la fábrica de Puntas de París de mi propiedad, se crea una nueva de mayor importancia, que necesitando doble número de operarios que aquella, ha de aumentar considerablemente el movimiento y la riqueza de este pueblo si la Providencia continúa, como hasta aquí, ayudando mi esfuerzo", en Archivo Municipal de Los 
terrenos complementarios para establecerse que, inexcusablemente, habrían de estar localizados junto a la fábrica de San Ignacio o muy próximos a ella.

El 20 de octubre de 1883 el corraliego compareció ante el notario de la municipalidad para oficializar la compraventa del inmueble junto a Dionisio González Agüeros Pastor, dedicado al comercio y vecino de la ciudad de Santander, quien actuó como representante de Juan, Josefa, Manuela, Ignacia y Juana Camus Pérez, unidos a Federico, Salvador, Vicenta y Adela Rosillo Quintana, esta última su esposa ${ }^{16}$. A referidos poderdantes les pertenecía en común y en diferentes porciones proindivisas el pleno dominio de la fábrica de harinas y sus adheridos, según la herencia de sus padres Fernando Rosillo y Francisco Camus Pérez y de la compra que efectuaron a Teresa Cos Quijano e hijos; siendo su deseo enajenar el conjunto, convinieron en autorizar la dación de poder a su cuñado y esposo en agosto de 1883, ante el notario público avecindado en la capital de la provincia, Lucio Valmaseda. Según consta en el documento, la descripción de los inmuebles era la que sigue:

"1 $1^{a}$ Una fábrica construida sobre el molino harinero comprado a la Nación, titulada San Ignacio, sita en término del lugar de Los Corrales y punto llamado de la Horcada [...]. No tiene número de gobierno y se halla asegurada de incendios en la compañía denominada Unión y Fénix.

2a Una casa habitación inmediata a repetida fábrica, edificada de nueva planta en dicho Los Corrales y sitio de la Horcada. Se compone de piso bajo principal y desván, cuadra y pajar, que mide treinta y cinco pies cuadrados, o sean nueve metros ochenta centímetros [...], sin número de gobierno y asegurada de incendios en repetida compañía Unión y Fénix.

$3^{a}$ Un prado en expresado Los Corrales y sitio de la Horcada, junto a mencionada fábrica, con árboles de nogal, álamos y de otra clase, cabida de cien carros, o sea una hectárea sesenta y nueve áreas [...].

$4^{\mathrm{a}}$ Otro prado también con árboles de nogal, álamo y alisa, al sitio llamado de la Pelambre, término [...] de Somahoz, a uno y otro lado del cauce que conduce las aguas a la referida fábrica de San Ignacio, dividido por nominado cauce en dos porciones; mide cincuenta y cinco carros

Corrales de Buelna, legajo A 145 núm. 92.

16 AHPC, protocolos notariales, legajo 7299, pp. 291-302. 
veinte y nueve céntimos, equivalentes a noventa y ocho áreas y noventa y ocho centiáreas $[\ldots]$.

5a Una faja de terreno labrantío en [...] mies del Agua, término de Somahoz, mide dos carros o tres áreas cincuenta y ocho centiáreas, cerrado [...], cuyo terreno puede servir para un apartadero desde el ferrocarril a mencionada fábrica [...].

Las fincas deslindadas constituyen o forman en el día una sola finca por ser todas necesarias para mayor servicio de la mencionada fábrica de San Ignacio"17.

La propiedad se tasó en nada menos que ochenta mil pesetas, de las cuales José María Quijano había entregado antes del auto y en metálico diecinueve mil; estas, sumadas a las mil pesetas que se rebajaron por la carga del censo a favor de José María Velarde del prado al sitio llamado de La Pelambre, hacían un total de veinte mil pesetas. El comprador se obligó a satisfacer la cuantía dentro de los tres años siguientes, cuyo plazo empezaría a contar precisamente desde el día en el que los herederos de Lorenzo Camus, fallecido abintestato, inscribieran en el registro de la propiedad la parte que heredaban de las fincas deslindadas. A partir de entonces, abonaría también a los vendedores el cinco por ciento de intereses de las sesenta mil pesetas restantes en cada uno de los tres años estipulados, quedando entretanto hipotecada la fábrica y los terrenos.

El 20 de octubre de 1883, fecha de la firma del documento de compraventa de la fábrica de San Ignacio, José María adquirió también dos fincas más, emplazadas en el término de San Felices ${ }^{18}$. Se trataba, por un lado, de un molino harinero bastante arruinado, compuesto de dos ruedas en el margen derecho del río Besaya, que medía siete metros de lado por cuatro metros veinte centímetros de frente; tenía, además, una posesión contigua de terreno labrantío y arbolado de álamos y lisos, con cabida de cinco con treinta y siete áreas. $Y$, por otro, un segundo molino arruinado sobre las aguas del mismo río, de cinco con sesenta centímetros de fondo por dos con ochenta metros de frente. Los hermanos Rosillo Quintana, que en virtud de la transacción hecha a Ignacio Pérez eran sus propietarios, decidieron transmitirlos con todos sus derechos por un valor de dos mil quinientas pesetas, con una condición: que, si en algún momento, el industrial vendiera la factoría, se las volviera a vender en igual precio.

17 AHPC, protocolos notariales, legajo 7299, pp. 291-302.

18 AHPC, protocolos notariales, legajo 7299, pp. 309-312. 


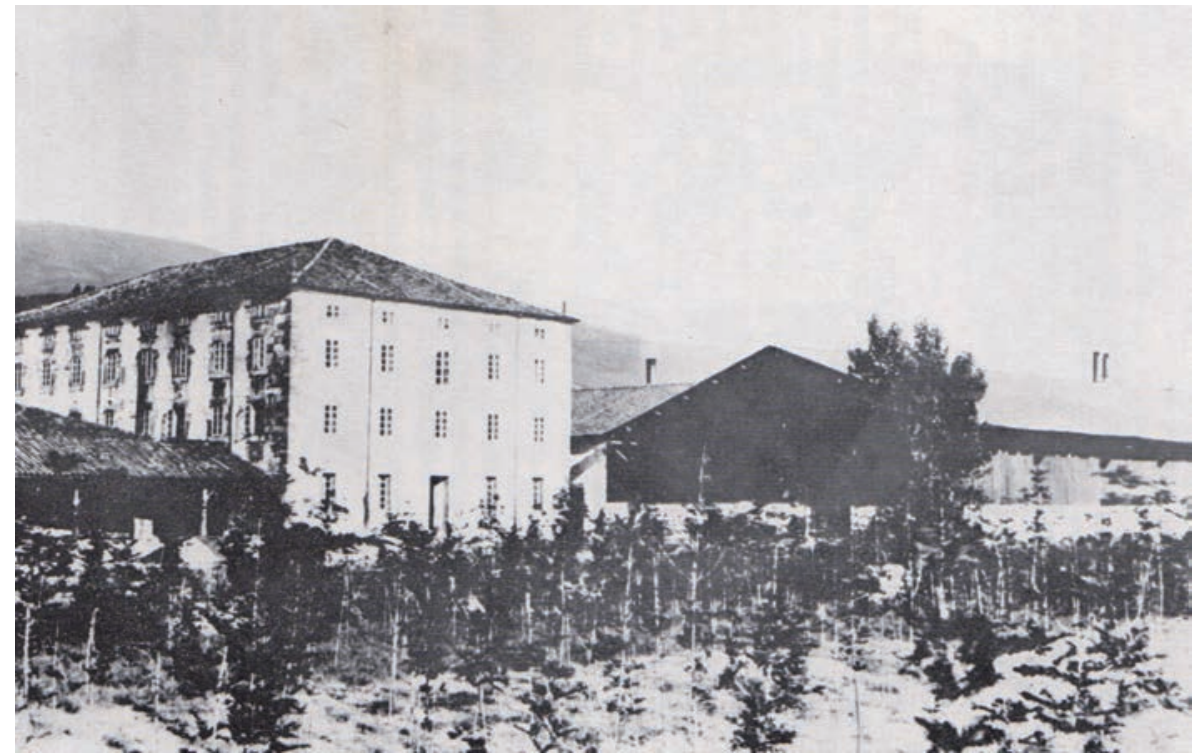

Fig. 3. Ángulo suroeste de la fábrica de San Ignacio. Autor desconocido. Década de 1940. Archivo de Trefilerías Quijano S.A. (Grupo CELSA). Los Corrales de Buelna

\section{2. De la harina al alambre}

La apariencia de la fábrica de San Ignacio y su configuración interna eran muy sencillas, respondiendo a una escueta tipología alejada de toda concesión estética ${ }^{19}$ (Fig. 1): un potente bloque rectangular de ciento veintiséis pies de largo por sesenta de ancho, aproximadamente de cuarenta por veinte metros, bajo más tres alturas o plantas y desván, cubierta a cuatro aguas con faldones que compartían una arista recta en la parte superior del tejado y, por tanto, no contaban con la misma inclinación. Al exterior, una estricta alineación de abundantes vanos adintelados, recercados con sillar bien escuadrado y protegidos por cristales con palillería.

El conjunto, tanto los terrenos y edificios como el mobiliario industrial y las mercancías, se mantuvo asegurado de incendios en la compañía de la Unión y el Fénix Español. La gestión, formalizada en noviembre de 1884, fue llevada a cabo por el corredor marítimo Modesto Piñeiro quien, desde su despacho en la santanderina calle del Muelle

19 "después, hace algunos años, una muy basta fábrica de harinas fue convertida en otra de alambres", en El correo de Cantabria, núm. 137, 15 de noviembre de 1897, p. 1. 
15, administraba los intereses del corraliego en otra casa de seguros marítimos, concretamente en La Española.

La fábrica de San Ignacio se convirtió en el embrión del segundo centro fabril de las Forjas de Buelna, el llamado de Arriba, donde se produciría el alambre directamente a partir de la palanquilla y fermachine recibidos de Bilbao; en el de en medio, o de La Aldea, se concentraría la elaboración de puntas de París, tachuelas, cadenas, soportes y demás manufacturas elaboradas a partir del preciado hilo de metal.

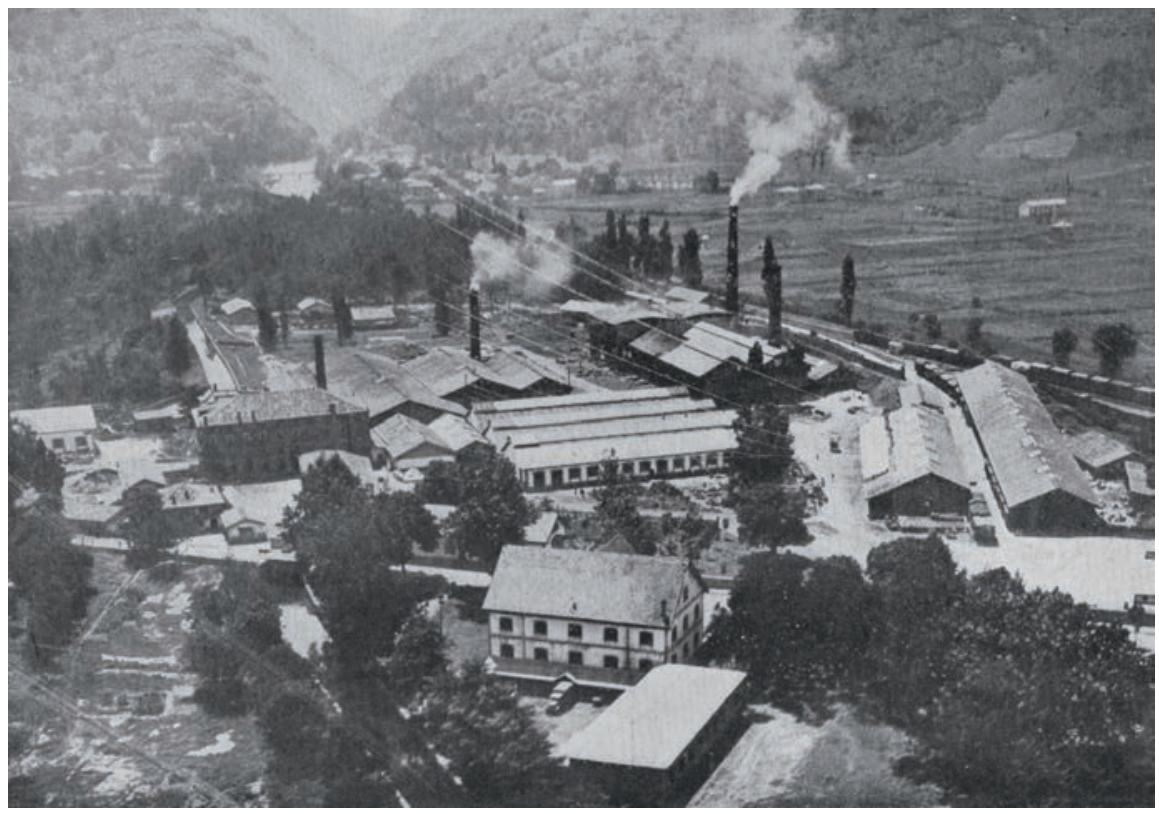

Fig. 4. Imagen fotográfica de las Forjas de Buelna, con la fábrica de San Ignacio representada en la mitad izquierda de la misma. Autor desconocido. Año 1950. Reproducida de El avance montañés: libro sobre la exposición del mismo nombre, Santander, Gobierno Civil de la Provincia de Santander, 1950

En el inmueble, se desarrolló la instalación completa de las secciones de trefilería y galvanizado, propuesta por la fábrica de máquinas y fundición de hierro propiedad de Wilhelm Gerhardi en Lüdenscheid, ciudad de Renania del Norte - Westfalia (Alemania). El complejo proyecto se fue modificando con el tiempo, hasta el punto de haber sido preciso que el propio Wilhelm Gerhardi se trasladara a Los Corrales de Buelna junto a Federico Vedder, representante de varias casas alemanas del sector en España, hecho que sucedió en el 
mes de septiembre de 1883. Entonces, pudo comprobar si la distribución de los espacios que había ideado era la correcta, si la trefilería de los números gruesos tendría tanta luz como necesitaba en la planta baja y si la de finos estaría bien situada en el piso alto; también le fue posible evaluar el engranaje del árbol de la turbina y cuál era la potencia del agua o la ubicación del galvanizado, para lo cual era preciso habilitar una instalación independiente porque el ácido y los vapores del zinc causaban una fuerte corrosión en todos los materiales próximos. La expectación en la provincia ante la inauguración de la segunda vida de la fábrica de San Ignacio era máxima, y la prensa local no podía menos que hacerse eco de tales emocionantes e ilusionantes noticias ${ }^{20}$.

La instalación de la trefilería necesitaba que la turbina encargada de aprovechar la potencia del agua tuviera una buena regulación automática. Como no era el caso, el contratiempo trató de resolverse, en primer lugar, con el reacondicionamiento del salto de agua, el mismo que, décadas atrás, favorecía la molienda de la preciada harina. La instalación proyectada sobre el río Besaya precisó el encargo de una nueva turbina. Intervino en el cometido Eduardo López-Dóriga y López-Dóriga († 1894), titulado ingeniero en Inglaterra, quien dirigió desde su constitución en 1877, junto a sus hermanos y otros socios, una importante industria metalúrgica en la capital santanderina, los Talleres de San Martín, ocupada en trabajos de fundición metálica, fabricación de maquinaria y reparación y construcción naval. El cariño que sentía hacia José María Quijano le llevó a seguir de cerca, y muy atentamente, los pasos que su amigo daba en el mundo de la industria; fue uno de sus auxiliares y asesores más fieles ${ }^{21} \mathrm{y}$ a su consejo se debió la introducción en la fábrica de no pocas innovacio-

20 "Actualmente se ocupa en montar la fábrica de alambre, que muy pronto comenzará a funcionar, $\mathrm{y}$, según personas competentes, a juzgar por la maquinaria que ha adquirido y por lo bien dispuestos que están los talleres, la fábrica de Los Corrales no tendrá nada que envidiar en materiales a la mejor de Francia y aún de Alemania", en El correo de Cantabria, núm. 344, 1 de octubre de 1884, p. 2.

21 Según el propio José María Quijano reconocía, "fue uno de los auxiliares más poderosos con que siempre conté. Mucho lo echo de menos y muy trascendental ha de ser para esta provincia su prematura muerte". Véase BUSTAMANTE QUIJANO, Ramón, José María Quijano: vida y obra de un hidalgo emprendedor, Santander, Nueva Montaña Quijano, 1986, p. 157. 


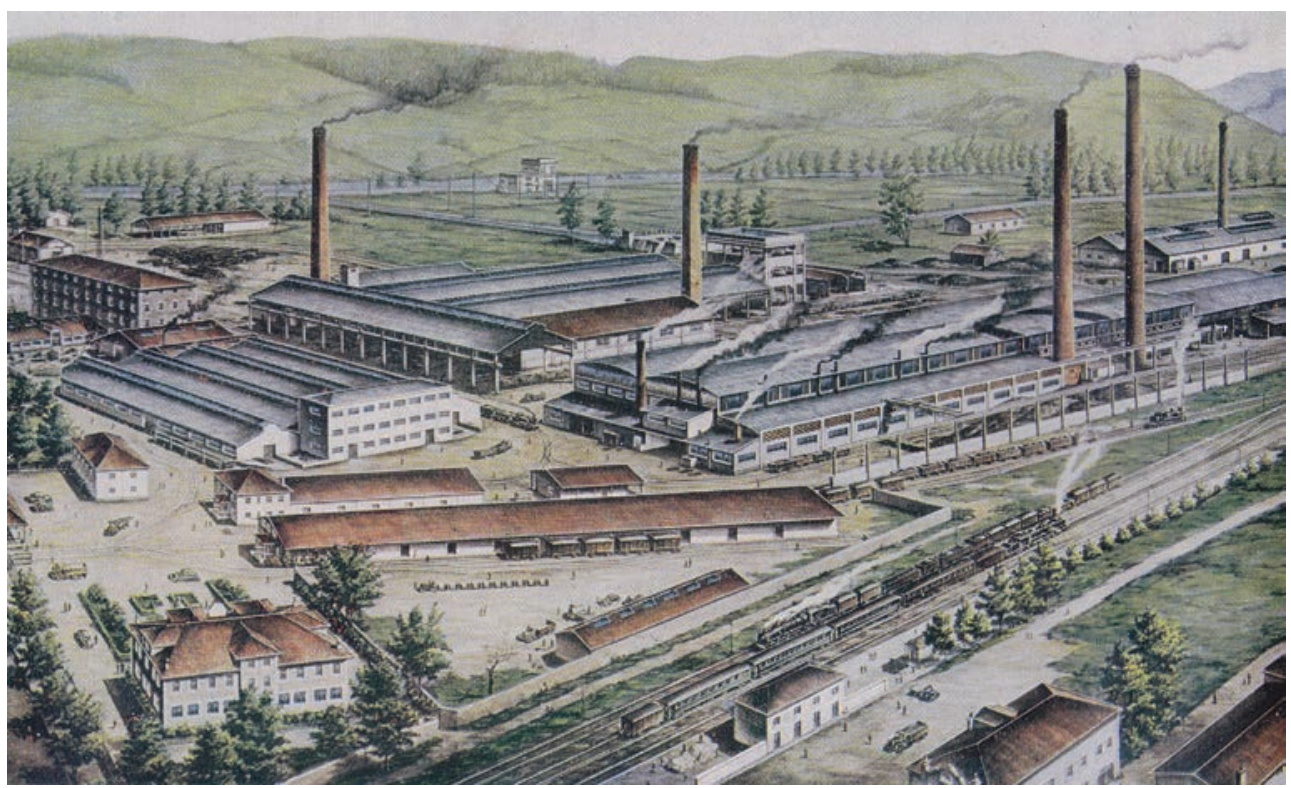

Fig. 5. Panorama del complejo de Arriba, con la fábrica de San Ignacio en la mitad superior izquierda. Autor desconocido. Década de 1950. Archivo de Trefilerías Quijano S.A.

(Grupo CELSA). Los Corrales de Buelna

nes, como el regulador de turbinas y ruedas hidráulicas patentado por el alemán Joahnn Georg Bodemer (1842-1916)22.

Después de múltiples percances, que aplazaban sine die la puesta en marcha de la nueva fabricación, la producción de alambre fue una realidad a principios de 1885 gracias a varios profesionales alemanes, llegados en primer término, y otros operarios oriundos de Toulouse, en un segundo. Estos se establecieron en el Valle de Buelna junto a sus familias durante varios años, gracias al primer grupo de viviendas que, ex profeso, construyó la empresa dirigida férreamente por José María Quijano, en el barrio de San Benito. La labor que unos y otros desarrollaron en la fábrica fue inestimable, tanto por la colaboración en el montaje de las nuevas instalaciones como porque lograron formar un equipo de avezados técnicos, gracias a la búsqueda y traslado de compatriotas y, especialmente, a la concienzuda instrucción de los obreros locales.

22 El 13 de octubre de 1883, el mismo Bodemer se manifestaba "très heureux de vous fournir les régulateurs desirés, dont vous serez fort satisfait", por un total de mil seiscientos cincuenta marcos, sin incluir ni embalaje ni envío. Véase Archivo de Trefilerías Quijano (Grupo CELSA), libros de correspondencia, 13 de octubre de 1883. 
A partir de entonces, la fábrica de San Ignacio acogería pacientemente la ampliación y continua renovación de la maquinaria y, de igual forma, pequeñas transformaciones en la distribución de los espacios interiores, como consecuencia de la introducción de nuevas técnicas de trabajo (Fig. 2). Calibradores, decenas de hileras que trabajaban en caliente y frío, bobinas ordinarias y también eléctricas, máquinas múltiples de estirar y otros muchos artilugios para la reparación colmataban un espacio en el que se produjeron, durante décadas, miles de toneladas de diferentes clases de alambre (galvanizado, cobrizo, brillante, etcétera).

\section{UN FATAL DESENLACE}

En la década de los años treinta del siglo XX, la fábrica de San Ignacio aún conservaba sus turbinas y cumplía la función de almacén. Su apariencia exterior apenas se había visto modificada con el paso de los años, si bien es cierto que se encontraba un tanto ensombrecida por las altas chimeneas y las complejas estructuras metálicas de los talleres que la flanqueaban (Fig. 3). Estos últimos se habían ido construyendo a medida que se hicieron más complejos los sistemas de producción y aumentaba el número de operarios, ofreciendo unas instalaciones más confortables que las propias de la decimonónica harinera.

Así ocurrió que, una vez quedó despojada de todo uso propiamente industrial, fue habilitada como residencia de obreros oriundos de otros municipios alejados; según Eugenio Sánchez Ruiz, se trataba de mano de obra sin cualificar, solteros o casados llegados junto a sus familias, que procedían, mayoritariamente, de Liébana, la parte alta de la cuenca del Besaya y la costa oriental de Asturias ${ }^{23}$. El total de dieciocho viviendas, con seis por cada una de las tres plantas, estaba lejos de ser una solución efectiva al sempiterno problema de las Forjas de Buelna, el del alojamiento de sus trabajadores, que superaban ampliamente la cifra de los dos mil en el año $1940^{24}$. Entonces, en plena sintonía con el nuevo uso, el inmueble fue apodado en el pueblo con los sobrenombres de La Casona, La Fondona y la Fonda del Sopapo (Fig. 4 y 5), como se recuerda entre los habitantes del pueblo.

23 SÁNCHEZ RUIZ, Eugenio, Las formas de intervención de la industria en la dinámica urbana de Los Corrales de Buelna, Santander, Universidad de Cantabria, 1986, p. 57.

24 Memoria-estadística del Comité de Seguridad e Higiene del Trabajo, Los Corrales de Buelna, Sociedad Anónima José María Quijano, 1942, sin paginar. 
El edificio de la originaria fábrica de harinas de San Ignacio fue demolido en los primeros años de la década de 1970, fagocitado por el ritmo de la industria automovilística, que desde hacía años acechaba sus terrenos. En el presente, no queda nada más que su memoria, escrita en diferentes documentos, pero también, y afortunadamente, su imagen. Los escasos testimonios iconográficos descubren un elemento de gran simplicidad estética, alejado de todo alarde superfluo en pro de una denodada funcionalidad e inserto en una realidad compleja, visible desde diferentes prismas que confluyen en una figura dotada meritoriamente de protagonismo.

\section{Fuentes}

Anuario-almanaque del comercio, de la industria, de la magistratura y de la administración, Madrid, Carlos Bailly-Baillière, 1879.

Anuario del comercio, de la industria, de la magistratura y de la administración, Madrid, Carlos Bailly-Baillière, 1881.

Archivo de Trefilerías Quijano (Grupo CELSA), libros de correspondencia, 13 de octubre de 1883.

Archivo Histórico Provincial de Cantabria, Catastro del Marqués de la Ensenada, legajo 257, p. 13.

Archivo Histórico Provincial de Cantabria, protocolos notariales, legajo 7293, pp. 416-423.

Archivo Histórico Provincial de Cantabria, protocolos notariales, legajo 7299, pp. 291-302 y 309-312.

Archivo Municipal de Los Corrales de Buelna, legajo A 145 núm. 92.

Boletín Oficial de la Provincia de Santander, núm. 24, 24 de febrero de 1860, p. 1. Boletín Oficial de la Provincia de Santander, núm. 96, 8 de febrero de 1865, p. 2.

El avance montañés: libro sobre la exposición del mismo nombre, Santander, Gobierno Civil de la Provincia de Santander, 1950.

El correo de Cantabria, núm. 137, 15 de noviembre de 1897, p. 1.

El correo de Cantabria, núm. 344, 1 de octubre de 1884, p. 2.

Memoria-estadística del Comité de Seguridad e Higiene del Trabajo, Los Corrales de Buelna, Sociedad Anónima José María Quijano, 1942, sin paginar.

\section{Bibliografía}

ANSOLA FERNÁNDEZ, Alberto y SIERRA ÁLVAREZ, José, Caminos y fábricas de harina en el Corredor del Besaya: historia, geografía y patrimonio, Torrelavega, Centro de Investigación del Medio Ambiente (CIMA), 2007. BUSTAMANTE QUIJANO, Ramón, José María Quijano: vida y obra de un hidal- 
go emprendedor, Santander, Nueva Montaña Quijano, 1986.

CANO SANCHIZ, Juan Manuel, “La fábrica de la memoria. La reutilización del patrimonio arqueológico industrial como medida de conservación", Antiquitas, 18-19 (2007), pp. 265-272, [consulta: 23 de agosto de 2018], disponible: https:/helvia.uco.es/bitstream/handle/10396/2956/ cano-fabricamemoria.pdf? sequence $=1 \&$ is Allowed $=y$.

CAPEL SÁEZ, Horacio, "La rehabilitación y el uso del patrimonio histórico industrial", Documents d'anàlisi geográfica, 29 (1997), pp. 19-50, [consulta: 23 de agosto de 2018], disponible: https://ddd.uab.cat/record/16356.

COLL Y PUIG, Antonio María, Guía consultor e indicador de Santander y su provincia, Santander, Imprenta de Evaristo López Herrero, 1875.

GIMÉNEZ Y GUITED, Francisco, Guía fabril e industrial de España, Madrid y Barcelona, Librería Española y Librería del Plus Ultra, 1862.

HOYO APARICIO, Andrés, Todo mudó de repente. El horizonte económico de la burguesía mercantil en Santander (1820-1874), Santander, Universidad de Cantabria y Asamblea Regional de Cantabria, 1993.

HOYO MAZA, Sara del, El industrial José María Quijano y su legado (18731950): de la fabricación de puntas de París a Nueva Montaña Quijano S.A., Oviedo, Universidad de Oviedo, 2012.

RÍO SAINZ, José Antonio del, La provincia de Santander, Santander, Imprenta de Salvador Atienza, 1875.

SÁIZ GONZÁLEZ, J. Patricio, “Susurros del Besaya. Artefactos y fábricas de un río cántabro", Actas del VIII Congreso Internacional para la conservación del patrimonio industrial, Madrid, Ministerio de Obras Públicas, Transportes y Medio Ambiente, 1995, pp. 411-421.

SÁNCHEZ RUIZ, Eugenio, Las formas de intervención de la industria en la dinámica urbana de Los Corrales de Buelna, Santander, Universidad de Cantabria, 1986.

TIELVE GARCÍA, Natalia, "La memoria del pasado industrial. Conservación, reutilización y creación de nuevos equipamientos", E-RPH. Revista electrónica de patrimonio histórico, 19 (2016), pp. 72-99, [consulta: 23 de agosto de 2018], disponible: http://revistaseug.ugr.es/index. php/erph/article/view/5500. 